with the European situation in some instances, striking differences in others, and distinct cultural and class variations on Western themes in still others. Everyone was challenged to find concepts adequate to analyzing diverse women's situations in a world experiencing similar and related phenomena-a world sharing dark times.

\title{
Women's Worlds: The Third International Interdisciplinary Congress on Women
}

\author{
Miranda Pollard \\ Columbia University
}

The Third International Interdisciplinary Congress on Women was held July 6-10, 1987, at Trinity College, Dublin. Bringing together over 1,400 feminists from fortyeight countries to discuss the theme "Women's Worlds: Visions and Revisions," this conference was an eclectic and excitingly different event. Previous congresses, held in Haifa (1981) and Groningen (1984) on "The New Scholarship" and "Strategies of Empowerment," brought together scholars from different disciplines and established this international conference as an ongoing event. (The congresses are somewhat miraculously organized without a permanent secretariat or parent institution.) Dublin in 1987 witnessed the congress's transformation into a major feminist conference. Indeed as an academic/political event, it gave plenty of material for reflection, providing its participants with an engaging if kaleidoscopic view of women's studies and feminist agendas in the late 1980s.

The chief message may have been the plurality of feminisms and even of academic women's studies. Any report must be partial and somewhat arbitrary. A coherent intellectual critique of the proceedings would be impossible, given that seven hundred papers were presented over five days and that each participant took away a quite different impression, sharing for the most part only the daily plenary sessions and the overall sense of a busy and diverse occasion. There were multiple panels on a range of areas such as women's history, literature, women and health, ecology, linguistics, science, spirituality, poverty, education, reproductive technologies, and art, with no hegemony of one political or intellectual approach. The plenary sessions included lectures by Helen Caldicott (Australia), Mary Daly (United States), Kamla Bhasin (India), and Birgit Brock-Utne (Norway) on peace activism, women's language, and women and development. The aim was "to bring together scholars and practitioners from a wide range of disciplines and areas of expertise to jointly explore issues of importance to women throughout the world." To dismiss the event (as one colleague did) as "hardly cutting-edge" academically is to miss the point. This conference was not an elite, self-referential academic exercise, but a more ambitious political event (at least in theory), most closely resembling the annual National 
Women's Studies Association Conferences among U.S. academic feminist gatherings. What seems significant in retrospect is the diversity of political issues raised and the possibilities for dialogue created.

The extraordinary number of panels was deliberately designed to showcase the greatest possible diversity of work-in-progress - and to give the greatest number of people fundable pretexts for attendance. Of course, it also meant a frustratingly brief and rapid advertising of diverse topics rather than a coherent working out of related subjects. A real "gift" of the conference was the fat book of abstracts that gave one an overview and a directory for following up on the work of particular speakers of interesting panels that you were unable to attend. What emerged throughout was a lively debate and an insistence on rethinking everything about this conference's purpose and organization.

While the organization seemed haphazard, this was no ordinary professionally arranged convention. There were many paradoxes of context, not least the role of women academics marginalized in their own institutions, which are largely hostile to feminist scholarship, confronting the militancy of feminists who have remained resolutely anti-intellectual. The format and purpose of an academic/international conference was confronted from the outset, for the Irish host committee's questions of access and structure were bitterly contested by (nonacademic) Irish feminists who saw this conference as a unique opportunity and resented the cost and numerical limitations on registration. The compromise resolution was the organization of a parallel set of community events - theater, music, art, bookstalls, etc. - and the integration into the main program of some activist and community workshops that addressed, at least partially, the needs of Irish feminists. On the other hand there was a failure to deal with the exorbitant cost of travel and registration for others, particularly Third World women, which meant that the majority of conference participants were employed and subsidized white U.S. academics. Foreign critics were slow to understand that high costs were partly due to the lack of fundraising possibilities and the high cost of everything in Ireland, a poor "peripheral" First World country.

The issues of legitimacy and privilege were articulated in other ways at the conference. While U.S. academics reported on their experience of curriculum development and institutionalization (and their sense of being relatively beleaguered), other feminists questioned the current nature of women's studies in a conservative climate and the degree of containment and cooptation that has taken place since the original feminist impetus of the late 1960s. The development of women's studies, for example, in the U.S., Great Britain and Ireland, and Australia, presents contrasting models for the significance and nature of the academy in relation to feminist goals, for the production and dissemination of feminist knowledge and in the manner in which institutional "tolerance" can mitigate or repress dissent and resistance.

If women's studies was one important topic, the direct connections of feminists to governmental politics was not lost sight of either. The threat of nuclear war and the processes of Third World development, for example, were the subjects of plenary sessions and workshops positing again an internationalist agenda, the issues of 
feminist unity and global inequities, the potential and difficulties for women's political mobilization on a local and international scale. Sessions on poverty, employment, and reproductive rights all claimed attention, but overall it was clear that no single issue and no single language of feminism sufficed or predominated.

The plenary on women in Ireland was a telling illustration of this diversity of outlooks. The reformist optimism, the universalizing and unifying good will of the keynote parliamentary speakers Mary Robinson and Monica Barnes as well as historian Margaret MacCurtain was abruptly contradicted by Ursula Barry, a feminist sociologist and activist, who insisted on the harsher realities and conflicts of Irish life (poverty, unemployment, emigration, sexual violence, homophobia) connecting the contemporary feminist struggle to an anti-imperialist analysis that clearly disquieted her colleagues, while the same analysis and her acerbic wit delighted the audience. Not coincidentally Irish media coverage ignored her contribution to this session and generally treated the conference as a bizarre jamboree.

The relationship of national and international communities was constantly invoked, highlighting the simultaneous specificity and interconnectedness of our feminisms and oppressions. Questions raised by discussions of the part played by women in national liberation struggles and the role of women in the "shrinking" global factory, teased out the different analyses (or lack of analysis) amongst feminists in attendance and gave a welcome reminder to the majority of U.S. feminists that women's studies is indeed intensely political and that our preoccupations must be with the structural, systemic nature of class, race, and gender oppressions.

The Fourth International Interdisciplinary Congress on Women will be held in 1990 at Hunter College in New York City. The venue is significant: the future in this city seems particularly bleak for women. The organizers promise more attention to organization, particularly fundraising and advertising, to enable greater non-U.S. participation. It remains to be seen how our agendas-feminist, political, and academic - will have developed by then and how tensions and preoccupations inherent in the experience of Dublin in 1987 will be played out.

\title{
Custom and Commerce in Early Industrial Europe
}

\author{
Edward Countryman
}

University of Warwick

This conference, held at the Center for the Study of Social History at the University of Warwick, in Coventry, April 24-26, 1987, was sponsored by the Economic and Social Research Council (ESRC) Working Group on Proto-Industrial Communities as the centerpiece of a series of symposia. Approximately fifty people took part, and the seventeen presenters represented nine different countries. 